\title{
AHPATININS, NEW ACID PROTEASE INHIBITORS CONTAINING 4-AMINO-3-HYDROXY-5-PHENYLPENTANOIC ACID
}

\author{
Satoshi Ōmura*, Nobutaka Imamura, Kazuhito Kawakita, Yōko Mori, \\ Yukiko Yamazaki, Rokurou Masuma, Yōko Takahashi, \\ Haruo Tanaka, Lee-Yuan HuanG ${ }^{\dagger}$ and H. Boyd Woodruff \\ The Kitasato Institute and School of Pharmaceutical Sciences, \\ Kitasato University, \\ Minato-ku, Tokyo 108, Japan \\ ${ }^{\dagger}$ Merck Sharp \& Dohme Research Laboratories, \\ Rahway, New Jersey 07065, U.S.A. \\ (Received for publication April 11, 1986)
}

\begin{abstract}
A soil isolate, Streptomyces sp. WK-142, was found to produce new acid protease inhibitors, ahpatinins A, B, D, E, F and G active against pepsin and renin. Ahpatinin $\mathrm{C}$ was found to be identical with pepstatin $A$. The structure determinations were based on mass spectral data. Four of the compounds contain the unusual amino acid, 4-amino-3-hydroxy5-phenylpentanoic acid as a building component.
\end{abstract}

In the course of our screening work for new acid protease inhibitors from actinomycetes, a strain WK-142, obtained from the rhizosphere of a bayberry plant growing at Tsumekisaki, Izu was found to produce new inhibitors, ahpatinins A, B, D, E, F and G, active against acid proteases, pepsin and renin.

This paper describes the taxonomy of the producing organism, fermentation, isolation, structure determination and enzyme-inhibiting activities of ahpatinins.

Taxonomy of the Producing Strain WK-142

\section{Morphology}

The vegetative mycelia of strain WK-142 grow abundantly on both synthetic and complex agar media and do not show fragmentation into cocoid or bacillary elements. The aerial mycelia grow abundantly on yeast extract - malt extract agar and inorganic salts - starch agar.

The spore chains are of the spiral type and have more than ten spores per chain (Plate 1). The spores are cylindrical in shape, $0.5 \times 0.9 \mu \mathrm{m}$ in size and have a smooth surface (Plate 1).

\section{Chemical Composition}

The chemical analysis of 2,4-diaminopimelic acid $\left(\mathrm{A}_{2} \mathrm{pm}\right)$ in the cell wall was carried out by the method of LeCHEVALIER and LeCHEVAlieR ${ }^{1}$. Strain WK-142 showed the presence of LL- $\mathrm{A}_{2} \mathrm{pm}$ in the cell wall.

\section{Cultural and Physiological Characteristics}

The International Streptomyces Project (ISP) media recommended by SHIRLiNg and GotTLIeB ${ }^{2)}$ and those recommended by WAKSMAN ${ }^{3)}$ were used. Cultures were observed after incubation at $27^{\circ} \mathrm{C}$ for two weeks. Color names and hue numbers indicated in Table 1 are those of the Color Harmony Manual (4th Ed) published by Container Cooperation of America. The utilization of carbon sources was tested by growth on PridHAm and GotTLieb's medium containing $1 \%$ of each carbon source at 
Table 1. Cultural characteristics of strain WK-142.

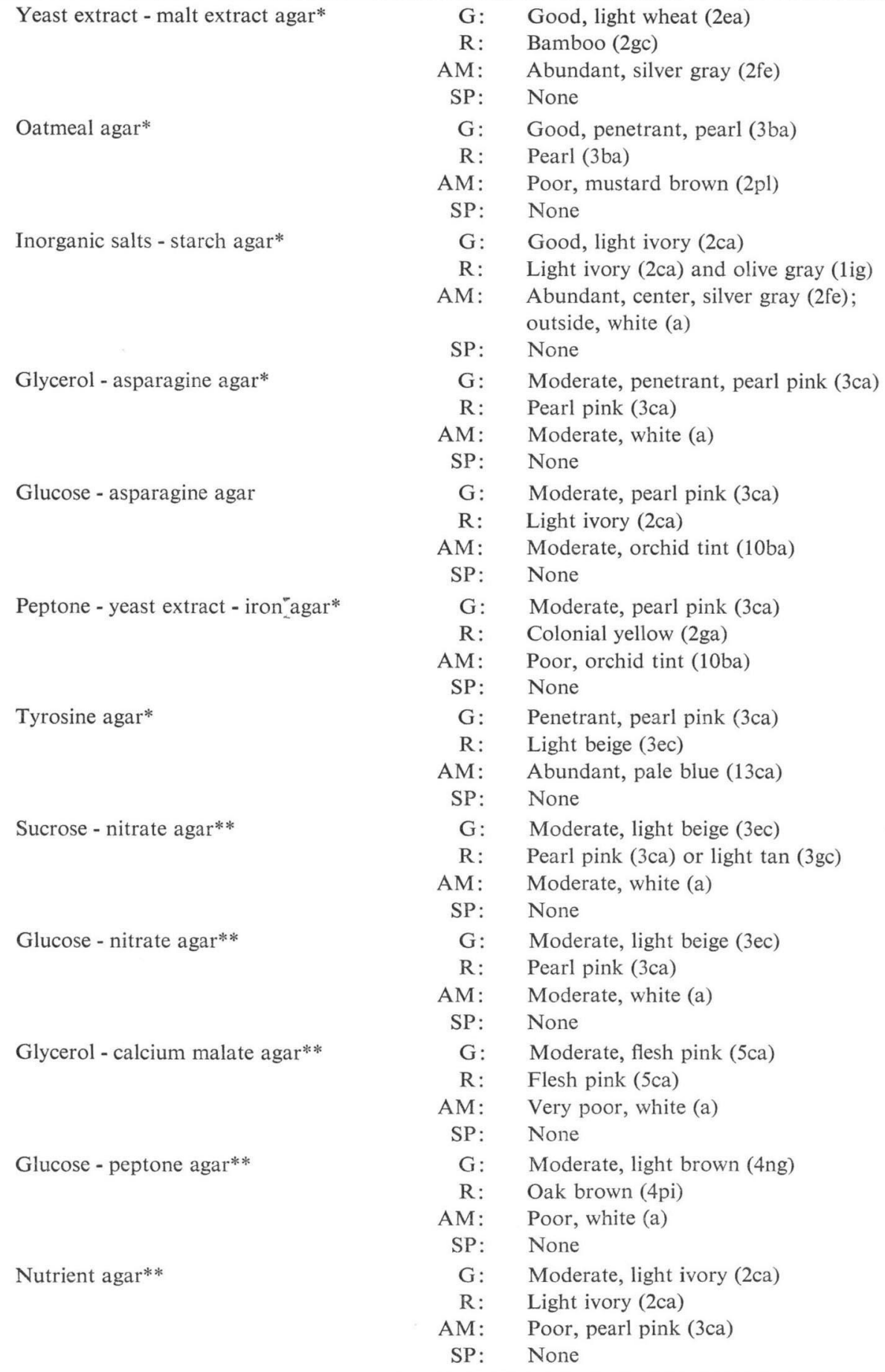

* Medium recommended by ISP ${ }^{2)}$.

** Medium recommended by S. A. WAKSMAN ${ }^{3)}$.

Abbreviations: $\mathrm{G}$; growth of vegetative mycelium, R; reverse, AM; aerial mycelium, SP; soluble pigment. 
Plate 1. Scanning electron-micrograph of spore chains of strain WK-142 on oatmeal agar.

Bar represents $1 \mu \mathrm{m}$.

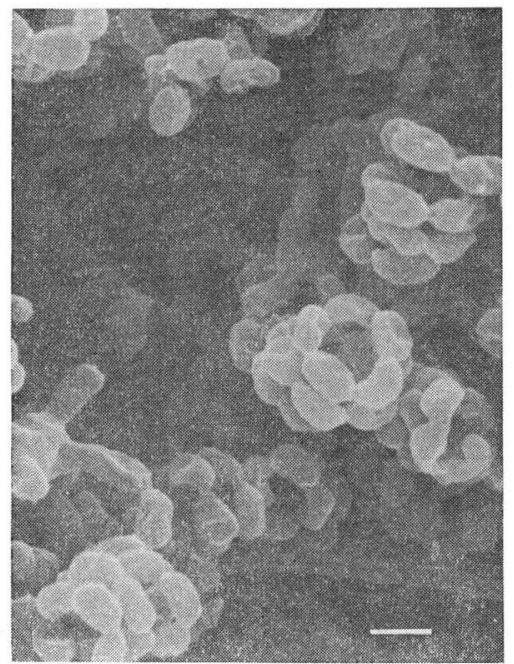

$27^{\circ} \mathrm{C}$. The cultural and physiological characteristics, and the utilization of carbon sources of strain WK-142 are shown in Tables 1, 2 and 3 , respectively.
Table 2. Physiological properties of strain WK-142.

\begin{tabular}{lc}
\hline Melanin formation & - \\
Tyrosinase reaction & - \\
$\mathrm{H}_{2} \mathrm{~S}$ production & - \\
Liquefaction of gelatin & - \\
Peptonization of milk & - \\
Coagulation of milk & + \\
Cellulolytic activity & - \\
Hydrolysis of starch & + \\
Temperature range for growth & $14 \sim 34^{\circ} \mathrm{C}$ \\
\hline+ ; Active, - ; not active.
\end{tabular}

Table 3. Utilization of carbon sources by strain WK-142.

\begin{tabular}{lc}
\hline D-Glucose & + \\
D-Fructose & + \\
L-Rhamnose & - \\
D-Mannitol & + \\
L-Arabinose & + \\
$i$-Inositol & + \\
Raffinose & + \\
D-Xylose & + \\
Sucrose & + \\
Melibiose & + \\
\hline
\end{tabular}

+ ; Utilized, - ; not utilized.

Strain WK-142 exhibits the following properties. Spore chain spiral; spore, cylindrical and smooth surface; color of vegetative mycelia, pearl pink or light ivory; color of aerial mycelia, white or gray; soluble pigment, none; $\mathrm{A}_{2} \mathrm{pm}$ in cell wall, LL type.

Based on the taxonomic properties described above, strain WK-142 is considered to belong to the genus Streptomyces and to be a strain of the white series or gray series of the PrIDHAM and TresNer grouping $^{4}$. Strain WK-142 has been deposited in the Fermentation Research Institute, Agency of Industrial Science and Technology, Japan, under the name Streptomyces sp. WK-142 and the accession No. FERM P-8448.

\section{Production and Isolation}

The stock culture of Streptomyces sp. WK-142 was inoculated into $100 \mathrm{ml}$ of a seed medium consisting of glucose $0.1 \%$, starch $2.4 \%$, peptone $0.3 \%$, meat extract $0.3 \%$, yeast extract $0.5 \%$ and $\mathrm{CaCO}_{3} 0.4 \%$ in a $500-\mathrm{ml}$ Erlenmeyer flask and incubated on a shaking machine at $27^{\circ} \mathrm{C}$ for 72 hours. Seven hundred milliliters of the seed culture was transferred into a 100-liter tank fermentor containing 70 liters of a production medium $\left(\mathrm{pH} 7.0\right.$ ) consisting of peptone $5.0 \%, \mathrm{NaCl} 0.5 \%, \mathrm{FeSO}_{4} \cdot 7 \mathrm{H}_{2} \mathrm{O}$ $0.001 \%, \mathrm{MnCl}_{2} \cdot 4 \mathrm{H}_{2} \mathrm{O} 0.001 \%, \mathrm{ZnSO}_{4} \cdot 7 \mathrm{H}_{2} \mathrm{O} 0.001 \%, \mathrm{CuSO}_{4} \cdot 5 \mathrm{H}_{2} \mathrm{O} 0.001 \%$ and $\mathrm{CoCl}_{2} \cdot 6 \mathrm{H}_{2} \mathrm{O} 0.001 \%$ and the aerobic fermentation was carried out at $27^{\circ} \mathrm{C}$. Production of inhibitors started at 48 hours after the inoculation, then gradually increased and reached the maximum at 72 hours. The cultured broth (70 liters) was centrifuged to obtain about 65 liters of a supernatant fluid. The supernatant was adjusted to $\mathrm{pH} 3.0$ with conc $\mathrm{HCl}$ and extracted with ethyl acetate (20 liters). The active principles were transferred from the organic layer into $0.1 \mathrm{~N} \mathrm{NH}_{4} \mathrm{OH}$ (5 liters), then the water layer was adjusted to $\mathrm{pH} 2.0$ and re-extracted with ethyl acetate ( 1 liter). The extract was concentrated to a small volume 
$(50 \mathrm{ml})$ in vacuo. The concentrate was poured into $n$-hexane $(500 \mathrm{ml})$ to yield active precipitate (dry weight, $840 \mathrm{mg}$ ). The crude material was chromatographed on a silica gel column with chloroform methanol. The active fractions were combined and evaporated to dryness. The resulting brown material $(410 \mathrm{mg}$ ) was dissolved in $50 \mathrm{ml}$ of $30 \%$ aqueous acetonitrile and applied on 10 pieces of SEPPAK $\left(\mathrm{C}_{18}\right)$ cartridges. The cartridges were washed with $30 \%$ and $50 \%$ acetonitrile, and then eluted with $80 \%$ acetonitrile. The eluate was evaporated to dryness, the resulting brown solid $(29.1 \mathrm{mg})$ was dissolved in acetic acid (100 $\mu \mathrm{l})$, and charged on a preparative HPLC (ODS) column and developed with $42.5 \%$ acetonitrile containing $0.2 \%$ acetic acid. Seven active compounds, A (1.39 mg), B (1.75 $\mathrm{mg}), \mathrm{C}(5.17 \mathrm{mg}), \mathrm{D}(1.54 \mathrm{mg}), \mathrm{E}(3.45 \mathrm{mg}), \mathrm{F}(1.13 \mathrm{mg})$ and $\mathrm{G}(0.55 \mathrm{mg})$ were obtained. Component $\mathrm{C}$ was identified with pepstatin $\mathrm{A}^{5)}$ by co-HPLC with an authentic sample and through the EI-MS

Fig. 1. IR spectrum of ahpatinin E.

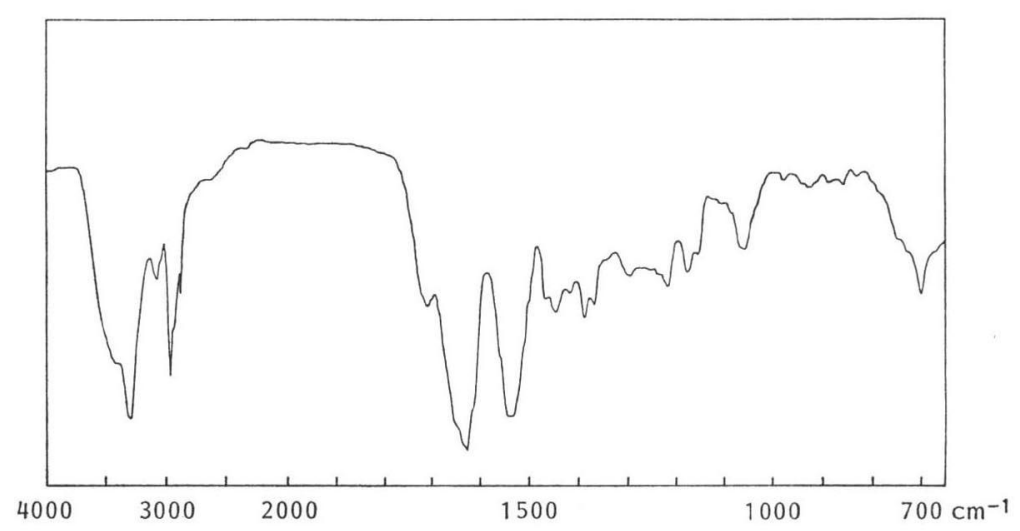

Fig. 2. ${ }^{1} \mathrm{H}$ NMR spectrum of ahpatinin $\mathrm{E}(400 \mathrm{MHz})$.

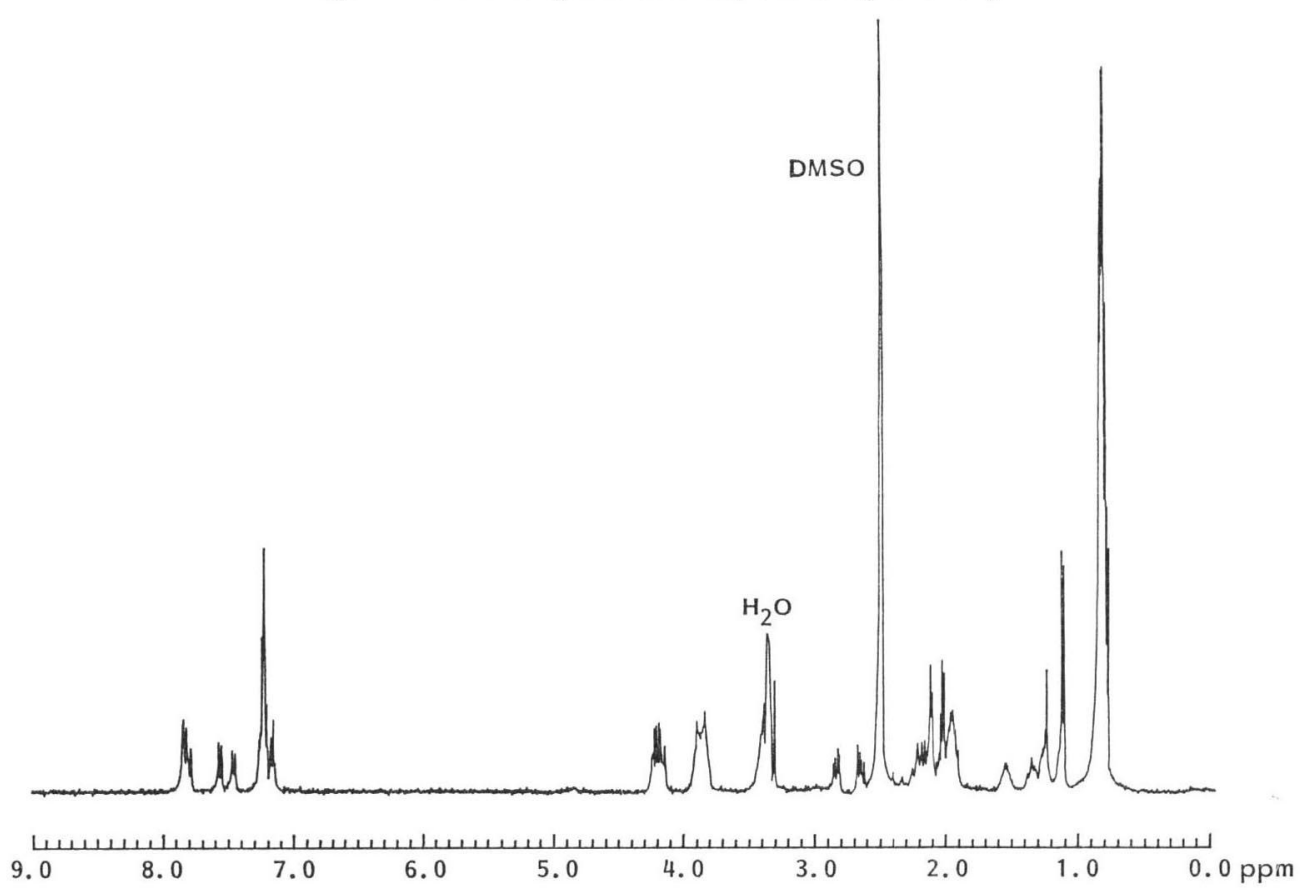


$\left(\mathrm{m} / z 699\left(\mathrm{M}^{+}\right)\right)$pattern.

\section{Physico-chemical Properties and Structures}

The active components were soluble in dimethyl sulfoxide, slightly soluble in water and methanol. Component $\mathrm{E}$ crystallized from water - acetonitrile in the form of colorless needles, $\mathrm{mp} 312 \sim 313^{\circ} \mathrm{C}$ (dec). The IR spectrum (Fig. 1) showed peptide bond absorption. The UV ( $\lambda_{\max }^{\mathrm{MeOH}} \mathrm{nm}(\varepsilon) 252$ (648), 258 (648), 264 (583), 267 (540)) spectrum of component E suggested the presence of a mono-substituted benzene ring. The molecular formula was found to be $\mathrm{C}_{37} \mathrm{H}_{61} \mathrm{~N}_{5} \mathrm{O}_{9}$ by the high-resolution mass spectrum data of its methyl ester (calcd for $\mathrm{C}_{38} \mathrm{H}_{61} \mathrm{~N}_{5} \mathrm{O}_{8} 715.452\left(\mathrm{M}-\mathrm{H}_{2} \mathrm{O}\right)^{+}$, found 715.451) and elemental analysis (calcd: C 61.73, H 8.54, N 9.73, found: C 62.02, H 8.65, N 9.65). A comparison of hydrolysates on TLC (silica gel, butanol - acetic acid - water, 3:1:1) of pepstatin $A$ and component $E$ indicated that the component $\mathrm{E}$ includes alanine, valine and statine moieties. The ${ }^{1} \mathrm{H}$ NMR spectrum in DMSO- $d_{e}$ (Fig. 2) indicated nine methyl groups (0.77 0.87 ppm, $24 \mathrm{H}$ and 1.11 ppm, Ala-methyl),

Fig. 3. EI-MS spectrum and fragmentation of ahpatinin E.
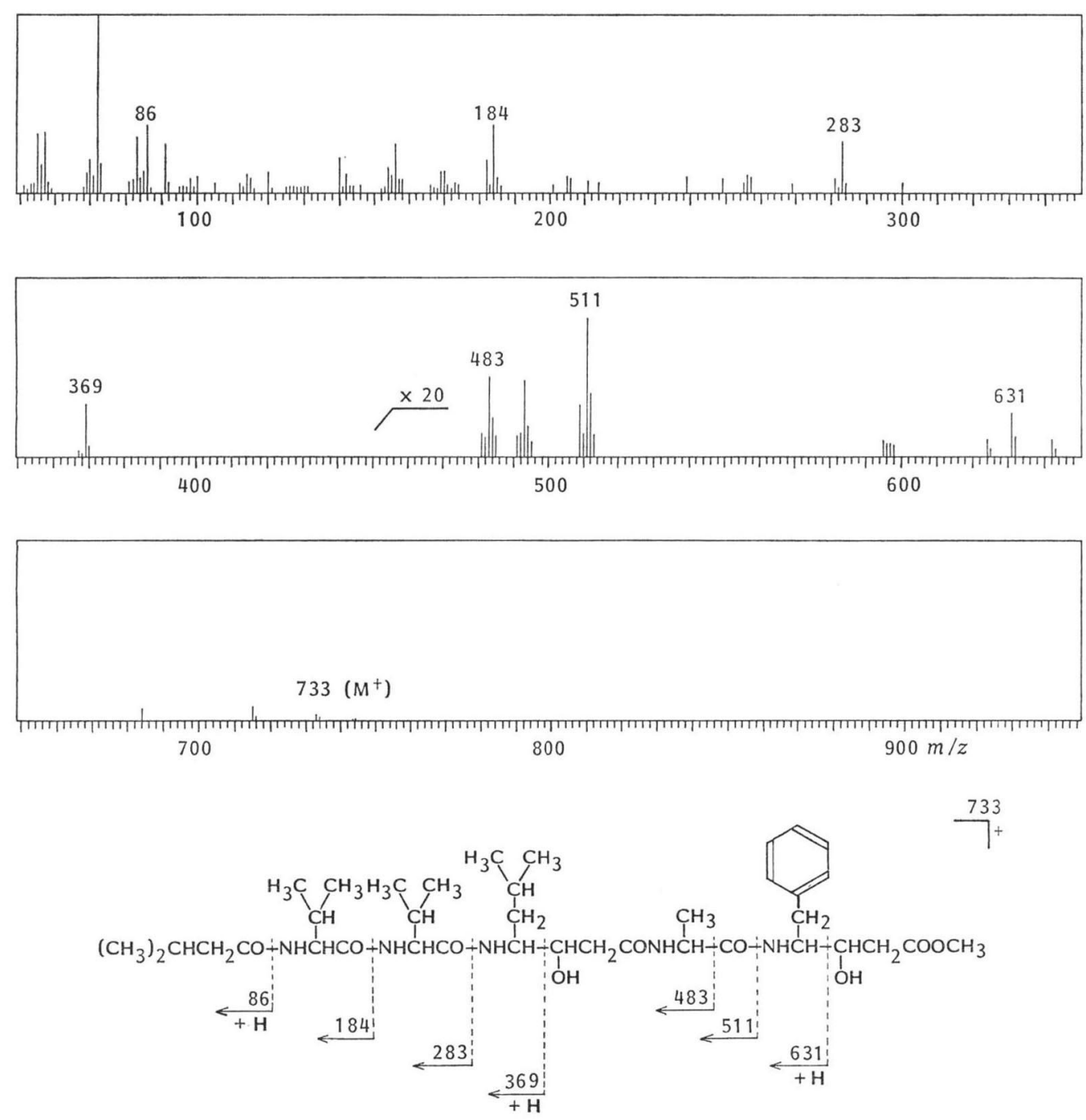
Table 4. Structures and MS fragment patterns of ahpatinins. Component $\mathrm{C}$ is identical with pepstatin $\mathrm{A}$.

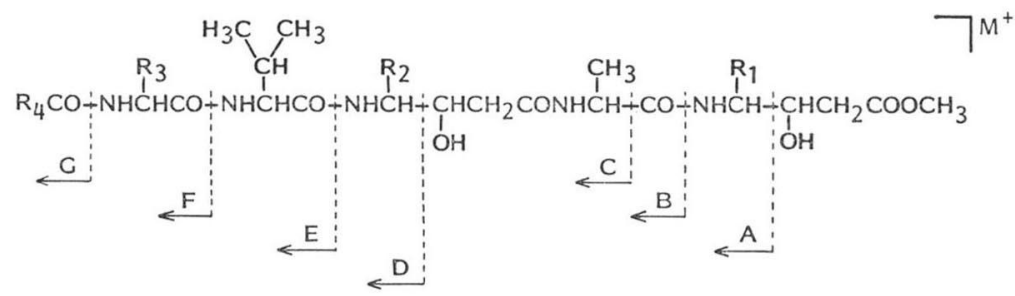

\begin{tabular}{|c|c|c|c|c|c|c|c|c|c|}
\hline \multirow{2}{*}{ Components } & \multicolumn{9}{|c|}{ Fragment ion peaks $(\mathrm{m} / \mathrm{z})$} \\
\hline & $\mathrm{M}^{+}$ & $(\mathrm{A}+\mathrm{H})^{+}$ & $\mathrm{B}^{+}$ & $\mathrm{C}^{+}$ & $(\mathrm{D}+\mathrm{H})^{+}$ & $\mathrm{E}^{+}$ & $\mathrm{F}^{+}$ & $(\mathrm{G}+\mathrm{H})^{+}$ & Others \\
\hline A & 719 & 617 & 497 & 469 & 355 & 269 & 170 & 72 & $\begin{array}{l}28\left(\mathrm{C}_{2} \mathrm{H}_{4}^{+}\right) \\
91\left(\mathrm{R}_{1}^{+}\right)\end{array}$ \\
\hline B & 719 & 617 & 497 & 469 & 355 & 269 & 170 & 72 & $91\left(\mathrm{R}_{1}^{+}\right)$ \\
\hline $\mathrm{C}$ & 699 & 597 & 511 & 483 & 369 & 283 & 184 & 86 & - \\
\hline $\mathrm{D}$ & 697 & 595 & 509 & 481 & 367 & 281 & 182 & 84 & - \\
\hline $\mathrm{E}$ & 733 & 631 & 511 & 483 & 369 & 283 & 184 & 86 & $91\left(\mathrm{R}_{1}^{+}\right)$ \\
\hline $\mathrm{F}$ & 733 & 631 & 545 & 517 & 403 & 317 & 218 & 86 & $190\left(\mathrm{~F}^{+}-\mathrm{CO}\right)$ \\
\hline G & 767 & 665 & 545 & 517 & 403 & 283 & 184 & 86 & $91\left(\mathrm{R}_{1}^{+}, \mathrm{R}_{2}^{+}\right)$ \\
\hline Components & \multicolumn{2}{|r|}{$\mathbf{R}_{1}$} & \multicolumn{3}{|c|}{$\mathrm{R}_{2}$} & \multicolumn{2}{|r|}{$\mathrm{R}_{3}$} & \multicolumn{2}{|r|}{$\mathbf{R}_{4}$} \\
\hline $\mathrm{A}$ & \multicolumn{2}{|c|}{$\mathrm{CH}_{2} \mathrm{C}_{6} \mathrm{H}_{5}$} & \multicolumn{3}{|c|}{$\mathrm{CH}_{2} \mathrm{CH}\left(\mathrm{CH}_{3}\right)_{2}$} & \multicolumn{2}{|c|}{$\mathrm{CH}\left(\mathrm{CH}_{3}\right)_{2}$} & \multicolumn{2}{|r|}{$\mathrm{C}_{3} \mathrm{H}_{7}$} \\
\hline B & \multicolumn{2}{|c|}{$\mathrm{CH}_{2} \mathrm{C}_{8} \mathrm{H}_{5}$} & \multicolumn{3}{|c|}{$\mathrm{CH}_{2} \mathrm{CH}\left(\mathrm{CH}_{3}\right)_{2}$} & \multicolumn{2}{|c|}{$\mathrm{CH}\left(\mathrm{CH}_{3}\right)_{2}$} & \multicolumn{2}{|r|}{$\mathrm{C}_{3} \mathrm{H}_{7}$} \\
\hline $\mathrm{C}$ & \multicolumn{2}{|c|}{$\mathrm{CH}_{2} \mathrm{CH}\left(\mathrm{CH}_{3}\right)_{2}$} & \multicolumn{3}{|c|}{$\mathrm{CH}_{2} \mathrm{CH}\left(\mathrm{CH}_{3}\right)_{2}$} & \multicolumn{2}{|c|}{$\mathrm{CH}\left(\mathrm{CH}_{3}\right)_{2}$} & \multicolumn{2}{|r|}{$\mathrm{CH}_{2} \mathrm{CH}\left(\mathrm{CH}_{3}\right)_{2}$} \\
\hline $\mathrm{D}$ & \multicolumn{2}{|c|}{$\mathrm{CH}_{2} \mathrm{CH}\left(\mathrm{CH}_{3}\right)_{2}$} & \multicolumn{3}{|c|}{$\mathrm{CH}_{2} \mathrm{CH}\left(\mathrm{CH}_{3}\right)_{2}$} & \multicolumn{2}{|c|}{$\mathrm{CH}\left(\mathrm{CH}_{3}\right)_{2}$} & \multicolumn{2}{|r|}{$\mathrm{C}_{4} \mathrm{H}_{7}$} \\
\hline $\mathrm{E}$ & \multicolumn{2}{|c|}{$\mathrm{CH}_{2} \mathrm{C}_{8} \mathrm{H}_{5}$} & \multicolumn{3}{|c|}{$\mathrm{CH}_{2} \mathrm{CH}\left(\mathrm{CH}_{3}\right)_{2}$} & \multicolumn{2}{|c|}{$\mathrm{CH}\left(\mathrm{CH}_{3}\right)_{2}$} & \multicolumn{2}{|r|}{$\mathrm{CH}_{2} \mathrm{CH}\left(\mathrm{CH}_{3}\right)_{2}$} \\
\hline $\mathrm{F}$ & \multicolumn{2}{|c|}{$\mathrm{CH}_{2} \mathrm{CH}\left(\mathrm{CH}_{3}\right)_{2}$} & \multicolumn{3}{|c|}{$\mathrm{CH}_{2} \mathrm{CH}\left(\mathrm{CH}_{3}\right)_{2}$} & \multicolumn{2}{|c|}{$\mathrm{C}_{6} \mathrm{H}_{5}$} & \multicolumn{2}{|r|}{$\mathrm{CH}_{2} \mathrm{CH}\left(\mathrm{CH}_{3}\right)_{2}$} \\
\hline $\mathrm{G}$ & \multicolumn{2}{|c|}{$\mathrm{CH}_{2} \mathrm{C}_{8} \mathrm{H}_{5}$} & \multicolumn{3}{|c|}{$\mathrm{CH}_{2} \mathrm{C}_{8} \mathrm{H}_{5}$} & \multicolumn{2}{|c|}{$\mathrm{CH}\left(\mathrm{CH}_{3}\right)_{2}$} & \multicolumn{2}{|r|}{$\mathrm{CH}_{2} \mathrm{CH}\left(\mathrm{CH}_{3}\right)_{2}$} \\
\hline
\end{tabular}

one benzyl methylene (2.64 and $2.83 \mathrm{ppm})$, five aromatic protons $(7.15 \sim 7.26 \mathrm{ppm})$, and five amide protons (7.46 (d) ppm, 7.56 (d), 7.80 (d), 7.84 (d) and 7.85 (d)). These data suggested that component E was an $N$-acyl-pentapeptide.

The MS spectrum of pepstatin A (component C) methyl ester indicated significant fragment ion peaks, i.e. $m / z 699\left(\mathrm{M}^{+}\right), 597,511,483,369,283,184$ and 86. The components of ahpatinins also demonstrated the similar MS fragment patterns, for example, the MS spectrum of component E methyl ester is shown in Fig. 3. The ion peak $m / z 631$ was attributable to the $\left(\mathrm{M}-\mathrm{C}_{4} \mathrm{H}_{8} \mathrm{O}_{3}\right)^{+}$ion peak and the other peaks, $m / z 511,483,369,283,184$ and 86 were identical to those of pepstatin A. The difference of $\mathrm{m} / z 631$ and $\mathrm{m} / z 597$ in pepstatin A methyl ester clearly indicated the structural difference between component $\mathrm{E}$ and pepstatin $\mathrm{A}$. Since component $\mathrm{E}$ contained a benzene ring as mentioned above, it must have a benzyl group instead of the isobutyl group in the $C$-terminal statine of pepstatin A. The structures of the other components were similarly determined through the MS data as demonstrated in Table 4. The components A and B seem to be geometrical isomers of the acyl group. The fragment pattern was confirmed by high-resolution MS data. The unusual amino acid, 4-amino-3-hydroxy-5-phenylpentanoic acid (AHPPA) is the first finding from a natural source.

Acid Protease Inhibiting Activities

It was reported that the acid protease inhibitors such as pepstatins exhibited potent inhibiting 
activities against pepsin and cathepsin $\mathrm{D}$ but very weak activity against renin ${ }^{6)}$. The inhibiting activities of ahpatinins were measured against pepsin and renin compared with pepstatin A.

The assay method of pepsin or renin was essentially that of ANSON ${ }^{7)}$ or IKEDA et al. ${ }^{8)}$ but modified slightly to give more sensitivity and reproducibility. Each component inhibited not only pepsin but also renin activity. The components showed similar pepsin-inhibiting activities, while they were different in their ability to inhibit renin. When the $\mathrm{IC}_{50}$ ratios against both enzymes were measured, that of pepstatin $\mathrm{A}$ was 3,000 while the $\mathrm{IC}_{50}$ ratios of the other components were in the range of 100 to 1,000 , component $\mathrm{G}$ showing the lowest value. Thus, the renin-inhibiting activities of these components are higher than that of pepstatin $\mathrm{A}$.

\section{Discussion}

Ahpatinins A, B, E and G contain the unusual amino acid, AHPPA, and components D and F include an unsaturated acyl group and phenylglycine, respectively. Although several compounds of the pepstatin group were described ${ }^{\theta, 10}$, no compound containing AHPPA, phenylglycine or an unsaturated acyl group has been reported. Thus ahpatinins A, B, D, E, F and G are new acid protease inhibitors. Ahpatinin G containing two AHPPA moieties is the most potent inhibitor of renin among ahpatinins and pepstatin A.

The $C$-terminal statine of pepstatin is considered to be not essential for the pepsin inhibitory activity. The central one should be the most important binding site to pepsin ${ }^{6)}$. Numerous model compounds containing a statine moiety or its analogs were synthesized ${ }^{11}$. Among these compounds, the tetrapeptide containing AHPPA instead of statine was as active against pepsin as the statinecontaining one. Since component $\mathrm{E}$ which contains AHPPA instead of the $C$-terminal statine of pepstatin A showed higher renin-inhibiting activity than pepstatin A, the $C$-terminal AHPPA seems to be an important binding site to renin.

\section{Acknowledgment}

We wish to thank Miss MAHO NIWA for the enzyme assays.

\section{References}

1) Lechevalier, M. P. \& H. A. Lechevalier: The chemotaxonomy of actinomycetes. Proc. of Papers of Actinomycete Taxonomy Workshop. pp. $1 \sim 49$, Soc. Ind. Microbiol., Aug. 13, Texas, 1978

2) Shirling, E. B. \& D. Gottlieb: Methods for characterization of Streptomyces species. Int. J. Syst. Bacteriol. 16: 313 340, 1966

3) Waksman, S. A.: The Actinomycetes. Vol. 2. Williams \& Wilkins Co., Baltimore, 1961

4) Pridham, T. G. \& H. D. Tresner: Genus I. Streptomyces Waksman and Henrici 1943, 339. In Bergey's Manual of Determinative Bacteriology. 8th Ed., Eds., R. E. Buchanan \& N. E. Gibbons, pp. 748 829, Williams \& Wilkins Co., Baltimore, 1974

5) Morishima, H.; T. Takita, T. Aoyagi, T. Takeuchi \& H. Umezawa: The structure of pepstatin. J. Antibiotics 23: $263 \sim 265,1970$

6) Aoyagi, T.; H. Morishima, R. Nishizawa, S. Kunimoto, T. Takeuchi \& H. Umezawa: Biological activity of pepstatins, pepstanone $\mathrm{A}$ and partial peptides on pepsin, cathepsin D and renin. J. Antibiotics 25: $689 \sim 694,1972$

7) Anson, M. L.: The estimation of pepsin, trypsin, papain and cathepsin with hemoglobin. J. Gen. Physiol. 22: 79 89, 1938

8) Ikeda, I.; K. Innuma, M. Takai, Y. Yanagawa, K. Kurata, T. Ogihara \& Y. Kumahara: Measurement of plasma renin activity by a simple solid phase radioimmunoassay. J. Clin. Endocrinol. Metab. 54: $423 \sim 428,1982$

9) Miyano, T.; M. Tomiyasu, H. Irzuka, S. Tomisaka, T. Takita, T. Aoyagi \& H. Umezawa: New pepstatins, pepstatins B and C, and pepstanone A, produced by Streptomyces. J. Antibiotics 25: 489 491, 1972

10) Aoyagi, T.; Y. Yagisawa, M. Kumagai, M. Hamada, H. Morishima, T. Takeuchi \& H. Umezawa: New pepstatins, pepstatins Bu, Pr and Ac produced by Streptomyces. J. Antibiotics 26: 539 541, 1973

11) Rich, D. H.: Pepstatin-derived inhibitors of aspartic proteinases. A close look at an apparent transition-state analogue inhibitor. J. Med. Chem. 28: 263 278, 1985 